\title{
Some Observations on the Cultivation, Fruiting and Germination of Fuligo septica
}

\author{
By PATRICIA M. SCHOLES* \\ Department of Microbiology, University of Reading
}

(Received 27 November 1961)

\begin{abstract}
SUMMARY
Conditions optimal for the laboratory culture of unpurified Fuligo septica plasmodium were examined. The organism was grown in the laboratory for over 2 years, during which time regular sporulation occurred. Investigation of factors which affected sporulation suggested that this was induced by material present in older cultures; light did not precipitate it. Spore germination occurred readily in the laboratory; some experiments on germination were made. $F$. septica plasmodium was purified by a migration technique combined with antibiotic treatment. Two-member cultures were established with two yeasts and a Penicillium sp. isolated from plasmodium, and with a baker's yeast. Several other organisms (including Gram-positive and Gram-negative bacteria and yeasts) were not satisfactory as associate organisms in two-member cultures. Satisfactory axenic culture was not obtained, slow growth for a few weeks only being obtained on an autoclaved suspension of baker's yeast.
\end{abstract}

\section{INTRODUCTION}

Much of the work carried out in recent years with members of the Class Myxomycetes has used Physarum polycephalum, since this organism proved able to grow abundantly in unpurified laboratory culture (Howard, 1931; Camp, 1936), was easily purified, and subsequently grown in two-member and in axenic culture (Howard, 1931; Cohen, 1939; Hok, 1954; Daniel \& Rusch, 1956, 1961). It readily completes its life cycle in the laboratory. Relatively few other myxomycetes have been grown in the laboratory throughout the whole of the life cycle (Alexopoulos, 1960; Gray, 1961), and fewer still have been grown in two-member or in axenic culture (Sobels, 1950; Hok, 1954; Kerr \& Sussman, 1958). It was therefore thought desirable to extend the range of organisms studied in this group of slime moulds. Work with the species Fuligo septica was begun since its spores are known to germinate readily and since it can produce large amounts of plasmodium under certain conditions, e.g. on heaps of spent tan in tanneries. The present aim was to produce axenic cultures and to investigate their nutritional requirements. However, considerable difficulty was experienced in the pursuit of this object and observations were made on the fruiting habit and spore germination of unpurified material whilst attempts were being made to produce purified material and to establish two-member and axenic cultures.

* Present address: Department of Microbiology, Queen Elizabeth College, University of London. 


\section{METHODS}

Source of organism. Fuligo septica sclerotium was collected from heaps of spent tan at the tannery of the Kingston Tanning Co., Ltd., Kingston-upon-Thames, Surrey. This sclerotium when placed on moistened filter paper in a humid chamber gave a typical bright yellow reticulate plasmodium.

Maintenance of stock cultures and preparation of inocula for experiments. Several culture media were tried. The best method of culture for the production of plasmodium for maintenance of stock cultures and for experimental purposes was found to be that of Camp (1936) in which pulverized rolled oats were fed to plasmodium supported on moist filter paper in a humid chamber. The culture vessel used was a 6 in. diameter Petri dish in which was placed the inverted half of a 4 in. diameter Petri dish wrapped in filter paper. A shallow layer of tap water was placed in the larger dish, to keep the filter paper moist and the atmosphere inside the larger dish humid, and the whole was autoclaved. It was found that there was less frequent overgrowth by contaminating organisms and better growth of the myxomycete when the oatmeal used was boiled in water, dried overnight (at $60^{\circ}$ ), ground to a fine powder and autoclaved (121 ${ }^{\circ}$ for $20 \mathrm{~min}$.). Stock cultures of Fuligo septica were maintained for more than 2 years in this way, being subcultured at monthly intervals and incubated at $\mathbf{2 5}^{\circ}$ in the dark.

Inocula for experiments were cut with a sterile scalpel from the advancing edge of the plasmodial reticulum of these cultures and were standardized as far as possible by taking a measured area $\left(0.25 \mathrm{~cm} . \times 0.25 \mathrm{~cm}\right.$.; $0.5 \mathrm{~cm} . \times 0.5 \mathrm{~cm}$.; or $\left.1.0 \mathrm{~cm} .{ }^{2}\right)$ which was transferred on the filter-paper support.

In recording results growth was estimated by measuring the area of plasmodium formed. This was not an accurate measure of growth since the plasmodial reticulum varied in density, but it gave sufficient information for the present purpose.

Experiments were carried out to determine optimal conditions for the growth of unpurified plasmodium, the effects of substrate, $\mathrm{pH}$ value, temperature, aeration, light and humidity being considered. Methods of purifying plasmodial material by migration and antibiotic treatments were investigated. Details of procedures are given in the next section together with results.

Tests for purity of plasmodium. Preliminary tests for purity of plasmodium were carried out by flooding with glucose yeast-extract broth and incubating at $25^{\circ}$ for 5 days washed agar plates across which plasmodium had been allowed to migrate. The washed agar was prepared by the method of Cohen, $1939 ; 2 \%$ agar was made up in $\mathrm{M} / 75$ phosphate at $\mathrm{pH} \mathrm{6.0.} \mathrm{The} \mathrm{agar} \mathrm{was} \mathrm{washed} \mathrm{before} \mathrm{use} \mathrm{in} \mathrm{running} \mathrm{tap}$ water for $24 \mathrm{hr}$. and in distilled water for $24 \mathrm{hr}$. This washed agar + phosphate medium will be referred to as Cohen's agar. When these preliminary tests of purification became negative plasmodium was transferred to a nutrient substrate. In this method of testing there was no evidence of false negatives due to inhibition of growth of any contaminants by antibiotics from the plasmodia (Sobels, 1948b). Confirmatory tests for pure cultures were then carried out by inoculating agar blocks (about $1 \mathrm{~cm} .{ }^{2}$ ) bearing plasmodial track from fresh Cohen's agar migration plates to the following media: malt agar, glucose yeast-extract agar, yeast-extract agar, peptone water, nutrient gelatin, thioglycollate broth, Robertson's cooked meat medium, medium for detection of cellulose-decomposing organisms. Aerobic 
incubation at $25^{\circ}$ of negative tests in all of these media was continued for three weeks, and anaerobic incubation at $25^{\circ}$ in the first five media for 3 days.

In all experiments unless otherwise stated plasmodium was incubated at $25^{\circ}$ in the dark in a humid atmosphere, incubation being in a closed container with a shallow layer of water in the bottom. Incubation of spores in experiments on germination was at $25^{\circ}$ in the dark.

\section{RESULTS}

\section{Optimal conditions for growth of unpurified Fuligo septica plasmodium}

Culture medium. The growth of Fuligo septica on a variety of media was examined: oatmeal agar ( $\mathrm{pH} 5,6)$, ground oatmeal scattered on Cohen's agar, aqueous extract and ethanolic extract of oatmeal (each sterilized by autoclaving), malt agar, nutrient gelatin, yeast-extract agar, glucose yeast-extract agar, glucose yeast-extract broth, tan-extract agar, Cohen's agar, living yeast suspension (Saccharomyces cerevisiae) spread on the surface of oatmeal agar, malt agar or

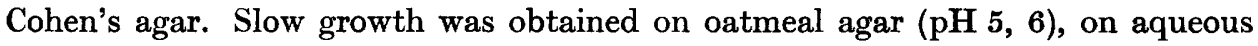
and ethanolic extracts of oatmeal, on malt agar and on tan-extract agar. When particulate nutrient was present on the surface of the agar, as in the case of oatmeal scattered on Cohen's agar and of yeast suspension on oatmeal agar, malt agar or plain agar, the growth was much improved. It was best on Cohen's agar + oatmeal where it was equal to that of controls set up as described for stock cultures. Several of the media used were toxic (nutrient gelatin, yeast-extract agar, glucose yeastextract agar and glucose yeast-extract broth), the plasmodium being dead within 2 days of inoculation in all cases. Control plasmodium on Cohen's agar survived for at least 14 days.

$p H$ value. Attempt was made to determine the optimal $\mathrm{pH}$ value for plasmodial growth by using as culture fluid in place of tap water, in cultures similar to those used for stock cultures, a series of buffer solutions (Sørensen) ranging from $\mathrm{pH} 3$ to 10. Suitable buffers were not found, however, those used in general being toxic at $\mathrm{M} / 15$ and having insufficient buffering power at lower concentrations. Determinations of $\mathrm{pH}$ value were made, however, over a 5-week period of incubation on the culture fluid of cultures maintained by the method described for stock cultures. The culture fluid, sterile tap water, had an initial $\mathrm{pH}$ value of 7.3. As growth of the plasmodium proceeded the $\mathrm{pH}$ value of the culture normally decreased from the initial value of $\mathrm{pH} \mathrm{7.3}$ to $\mathrm{pH} \mathrm{4.5-6.0}$ in 2-3 weeks, then becoming relatively constant (Table 1). In such cultures growth was good at all stages and in general the plasmodium presented a normal appearance, i.e. it was bright yellow in colour, formed a characteristic reticulum over the filter paper support and exhibited rapid streaming of protoplasm. When the $\mathrm{pH}$ value did not decrease in the usual way (e.g. culture 2 in Table 1 where the $\mathrm{pH}$ value rose to above $\mathrm{pH} 8$ ) growth was poor and the plasmodium abnormal in appearance until the $\mathrm{pH}$ eventually decreased.

Temperature. To examine optimal growth temperature cultures maintained as described for stock cultures were incubated at $25^{\circ}, 30^{\circ}$ and $37^{\circ}$ (at $25^{\circ}$ and $30^{\circ}$ for 6 months). Incubation was also carried out for a few weeks at room temperature $\left(18^{\circ}-20^{\circ}\right)$. The relative amounts of growth and the appearance of plasmodia were recorded. Table 2 shows typical results. Normal growth occurred, and continued for the 6-month period of the experiment, at $25^{\circ}$ and $30^{\circ}$, being more rapid at $30^{\circ}$. 
Table 1. Changes in $p H$ value of developing Fuligo septica cultures grown on ground oatmeal on a filter-paper support at $25^{\circ}$

\begin{tabular}{|c|c|c|c|c|c|c|c|c|c|}
\hline \multicolumn{7}{|c|}{ Days } & \multirow[b]{2}{*}{ 34 } & \multirow{3}{*}{ Growth } & \multirow{3}{*}{ Appearance } \\
\hline & 1 & 6 & 12 & 18 & 23 & 26 & & & \\
\hline \multicolumn{2}{|c|}{ Culture } & & I val & of cu. & re flu & & & & \\
\hline $\mathbf{I}$ & $7 \cdot 6$ & $6 \cdot 5$ & $6 \cdot 7$ & $4 \cdot 6$ & $4 \cdot 6$ & 4.5 & $4 \cdot 6$ & Good throughout & $\begin{array}{l}\text { Pale yellow becoming } \\
\text { normal at } 18 \text { days }\end{array}$ \\
\hline 2 & $8 \cdot 4$ & $8 \cdot 5$ & $8 \cdot 2$ & $7 \cdot 6$ & $7 \cdot 3$ & $6 \cdot 3$ & $5 \cdot 6$ & $\begin{array}{l}\text { Poor initially, im- } \\
\text { proving at about } \\
23 \text { days }\end{array}$ & $\begin{array}{l}\text { Pale yellow, plasmo- } \\
\text { dium densely massed; } \\
\text { becoming normal at } \\
\text { end of experiment }\end{array}$ \\
\hline 3 & $7 \cdot 6$ & $7 \cdot 8$ & $5 \cdot 4$ & $5 \cdot 2$ & $6 \cdot 5$ & $4 \cdot 9$ & $5 \cdot 0$ & Good throughout & \multirow{3}{*}{$\begin{array}{l}\text { Normal bright yellow } \\
\text { plasmodium showing } \\
\text { rapid streaming of } \\
\text { protoplasm }\end{array}$} \\
\hline 4 & $7 \cdot 6$ & $7 \cdot 2$ & $7 \cdot 3$ & $6 \cdot 2$ & $6 \cdot 8$ & $5 \cdot 9$ & $5 \cdot 9$ & Good throughout & \\
\hline $\begin{array}{l}5 \\
\mathbf{6}\end{array}$ & $\begin{array}{l}7 \cdot 8 \\
7 \cdot 1\end{array}$ & $\begin{array}{l}6 \cdot 5 \\
5 \cdot 6\end{array}$ & $\begin{array}{l}5 \cdot 3 \\
4 \cdot 8\end{array}$ & $\begin{array}{l}5 \cdot 1 \\
4 \cdot 8\end{array}$ & $\begin{array}{l}5 \cdot 7 \\
5 \cdot 4\end{array}$ & $\begin{array}{l}4 \cdot 7 \\
4 \cdot 7\end{array}$ & $\begin{array}{l}6 \cdot 8^{*} \\
5 \cdot 2\end{array}$ & $\begin{array}{l}\text { Excellent. More } \\
\text { rapid than in } \\
\text { cultures } 3 \text { and } 4\end{array}$ & \\
\hline
\end{tabular}

* Had fruited 5 days previously.

At $37^{\circ}$ no growth occurred and the inoculum died within 1 or 2 weeks. At room temperature $\left(18^{\circ}-\mathbf{2 0}{ }^{\circ}\right)$ growth was normal but slower than at the higher temperatures.

Anaerobic cultivation. Aerobic and anaerobic (95\% (v/v) hydrogen +5\% (v/v) carbon dioxide in a McIntosh and Fildes' jar) incubations of plasmodium were carried out on malt agar and on Cohen's agar. Fuligo septica behaved as an obligate aerobe under the conditions used; no growth or migration occurred during. anaerobic incubation, and the plasmodium died.

Table 2. Growth of Fuligo septica at various temperatures

The cultures were grown on ground oatmeal on a filter-paper support.

\begin{tabular}{|c|c|c|c|c|c|}
\hline \multirow[b]{3}{*}{ Temp. } & \multirow[b]{3}{*}{ Culture } & \multicolumn{4}{|c|}{ Growth and appearance at } \\
\hline & & \multicolumn{2}{|c|}{ One week } & \multicolumn{2}{|c|}{ Two weeks } \\
\hline & & $\begin{array}{c}\text { Plasmodial } \\
\text { area } \\
\left(\mathrm{cm} .^{2}\right)\end{array}$ & Appearance & $\begin{array}{c}\text { Plasmodial } \\
\text { area } \\
\left(\mathrm{cm} .^{2}\right)\end{array}$ & Appearance \\
\hline $25^{\circ}$ & $\begin{array}{l}\text { (i) } \\
\text { (ii) }\end{array}$ & $\begin{array}{r}8 \\
12\end{array}$ & $\begin{array}{l}\text { Normal } \\
\text { Normal }\end{array}$ & $\begin{array}{l}18 \\
14\end{array}$ & $\begin{array}{l}\text { Normal } \\
\text { Normal }\end{array}$ \\
\hline $30^{\circ}$ & $\begin{array}{l}\text { (i) } \\
\text { (ii) }\end{array}$ & $\begin{array}{l}25 \\
12\end{array}$ & $\begin{array}{l}\text { Normal } \\
\text { Normal }\end{array}$ & $\begin{array}{r}100 \\
41\end{array}$ & $\begin{array}{l}\text { Normal } \\
\text { Normal }\end{array}$ \\
\hline $37^{\circ}$ & $\begin{array}{l}\text { (i) } \\
\text { (ii) }\end{array}$ & $\begin{array}{c}\text { Dead } \\
1\end{array}$ & $\overline{\text { Contracted mass }}$ & $\overline{\text { Dead }}$ & - \\
\hline
\end{tabular}

Light. The effect of light on the plasmodium was observed by using culture methods as for temperature experiments. Incubation was carried out in daylight, including exposure for $2 \mathrm{hr}$. to direct afternoon sunlight, and in the dark. The plasmodium on being placed in light almost immediately developed 'swellings' which appeared to be formed by rapid streaming of the protoplasm through lesions in the plasmodial strands. This phenomenon has been observed previously in several myxomycetes (Baranetzki, 1876; Gray, 1938). The plasmodium was negatively 
phototactic, and after incubation for 4-5 days in light lost its pigmentation, becoming cream in colour. Initially growth was retarded in the light, but after 2 weeks the plasmodium appeared to return to normal apart from pigmentation.

Humidity. Plasmodial growth in humid (nearly saturated) and non-humid atmosphere was compared. Better growth was obtained in humid than in non-humid atmosphere.

\section{Purification of plasmodium}

Purification of Fuligo septica was attempted by several methods. The migration method of Cohen (1939) was unsuccessful with migration of $F$. septica plasmodium on Cohen's agar, even at the maximum migration rate of $0.5 \mathrm{~cm} . / \mathrm{hr}$. achieved at $30^{\circ}$. (Cohen related successful purification to speed of migration.) The present findings were contrary to those of Cohen who found that one strain of $F$. septica when migrating at only $1.5 \mathrm{~cm}$./day was readily purified by his method. The difference between Cohen's results and the present ones may have been due to differences in the accompanying microflora. Unsuccessful also were migration of plasmodium on other supports (silica gel, cellophan laid over Cohen's agar, glass, moistened filter paper), enrichment with Saccharomyces cerevisiae followed by migration (Cohen, 1939), treatment of plasmodium with ultraviolet radiation, and heat treatment of spores.

The method finally adopted was a combination of a migration technique with treatment by antibioties similar to that used by Sobels (1948a) and Hok (1950). Penicillin + streptomycin incorporated in Cohen's agar each at 2500 units/ml. were used. These high concentrations of antibiotic were necessary since one of the contaminating organisms was relatively resistant; the plasmodium was unaffected by these antibiotics. Migration over Cohen's agar + antibiotics was carried out for 2 days, followed by 1 day on Cohen's agar and a further 2 days on the antibiotic agar. This treatment removed bacterial contaminants in $90 \%$ of the tests, but yeast and mould contaminants persisted for longer. Further migration on Cohen's agar for as long as 18 days was necessary to complete the purification. An attempt was made to decrease this long migration period by using antifungal agents but those tested (griseofulvin, viridin, copper sulphate, cycloheximide, $o$-chlorophenol, $p$ chlorophenol, $\beta$-phenylethyl alcohol) were more toxic to the myxomycete than to the contaminating yeasts and moulds.

An alternative method of purification in which tubes were used for migration in place of Petri dishes was found to be convenient. The tubes were $40 \mathrm{~cm}$. long, $1 \mathrm{~cm}$. internal diameter, with each end (about $3 \mathrm{~cm}$.) bent up at an angle of $45^{\circ}$, and contained a shallow layer of Cohen's agar. The direction of movement of the plasmodium could be controlled when necessary by the negative phototactic response of the plasmodium when the tube was illuminated at one end. By using this combination of migration technique and antibiotic treatment $85 \%$ of the attempted purifications were successful. The method was tedious and the resulting plasmodial fragment usually only about $1 \mathrm{~mm} .{ }^{2}$, but no better method was found.

\section{Tro-member cultures}

Attempts were made to establish Fuligo septica plasmodium in two-member culture with ( $a$ ) organisms isolated from the plasmodium, $(b)$ various Gram-positive and Gram-negative bacteria from other sources. 
(a) Purified plasmodium was inoculated to malt agar $(10 \mathrm{ml}$. slopes in 6 in. $\times$ 1 in. tubes) together with one isolate from the plasmodium. Eight Gram-negative rods, five yeasts, and one Penicillium sp. were tested in this way as associate organisms. One of the Gram-negative rods and three of the yeasts were also inoculated with plasmodium on to Cohen's agar. When growth of the plasmodium occurred transfers were made through several subcultures to confirm establishment of true two-member culture.

Of the fourteen organisms tested only three were successfully established in twomember culture with the plasmodium. These were two yeasts (one white- and the other black-pigmented) and a Penicillium sp. Of these three organisms, the whitepigmented yeast gave growth comparable to that of unpurified cultures of plasmodium; the other yeast and the Penicillium sp. gave slightly less good growth. In one experiment a small amount of growth was obtained with one of the Gramnegative rods and with two other yeasts. This, however, was not repeatable. Malt agar was more satisfactory for two-member cultures than plain agar; better growth was obtained and the associate organisms did not need to be added at intervals since they grew on the malt agar. The white-pigmented yeast seemed to be the organism of choice for routine two-member cultures. The plasmodium was maintained on malt agar in association with this organism for $\mathbf{3}$ months without any deterioration of the myxomycete strain becoming apparent.

(b) Purified plasmodium was inoculated onto washed agar on which were streaked washed suspensions of various Gram-negative bacteria, Gram-positive bacteria and yeasts, previously grown in shaken glucose yeast-extract broth cultures at $30^{\circ}$ for $24 \mathrm{hr}$.: Pseudomonas fuorescens, Escherichia coli, Erwinia carotovorum, Serratia marcescens, Corynebacterium sp., Bacillus cereus, Micrococcus aurantiacus, Micrococcus flavus, Saccharomyces cerevisiae, Torula rosea. Incubation was as in (a). Of these ten organisms not isolated from plasmodium the Corynebacterium sp. permitted poor growth of plasmodium which deteriorated after a few days; Escherichia coli gave slow growth continuing for 2 weeks. Saccharomyces cerevisiae gave continuing growth of plasmodium on subculture; this was slower, however, than with the yeast isolated from the plasmodium.

\section{Axenic cultures}

The following preparations were tested as nutrients for pure cultures of Fuligo septica: sterile ground oatmeal; aqueous extract of oatmeal; ethanolic extract of oatmeal; oatmeal agar; autoclaved baker's yeast suspension in distilled water; yeast autolysates (one prepared from baker's yeast, dried, and incubated in distilled water at $37^{\circ}$ for $4 \mathrm{hr}$. and at room temperature overnight; the other from brewer's yeast, ground, incubated in distilled water at $50^{\circ}$ for $24 \mathrm{hr}$. and sterilized by autoclaving or by filtration); sand-ground brewer's yeast (sterilized by filtration); ethanol + ether-dried yeast; aqueous extract of baker's yeast; ethanolic extract of yeast; yeast disintegrated in a Mickle disintegrator (centrifuged at high speed to 'sterilize'); malt agar; Difco yeast-extract casein agar. The sterilization of these preparations was by autoclaving unless otherwise stated. In addition, purified plasmodium was placed on a cellophan membrane overlying a culture of living yeast (originally isolated from plasmodium) on malt agar.

Only one preparation of those tested gave any growth of plasmodium, namely, 
the autoclaved baker's yeast suspension in distilled water. The growth was, however, very slow as compared with that of the control and the plasmodium began to deteriorate after 3 weeks. At no times was the plasmodium normal in appearance, being pale yellow instead of a bright deeper yellow. A similar autoclaved yeast preparation incorporated in the agar did not support growth of the plasmodium.

The yeast autolysates and the Difco yeast-extract casein agar were toxic to the plasmodium (cf. results with unpurified cultures; also observations on Physarum polycephalum reported by Hok, 1950).

\section{Sporulation of Fuligo septica in laboratory culture}

The following observations were made with unpurified plasmodium on the effect on sporulation of the age of the culture and of various environmental conditions.

Age of culture. The sporulation of two groups of Fuligo septica cultures was observed over a period of 2 years. Both groups of cultures were set up as described for stock cultures and were fed with the oatmeal preparation at weekly intervals. One group was subcultured every 4 weeks and the second group was maintained without subculture until sporulation occurred, sclerotium was formed or the plasmodium died. Humid conditions were maintained by adding sterile tap water when necessary.

Subculture of plasmodium to fresh medium prevented sporulation; of 171 cultures observed only $7(4 \%)$ sporulated within 28 days. On the contrary the cultures maintained under exactly similar conditions but without subculture showed a relatively high percentage of sporulation throughout the entire 2-year period; of 171 cultures observed $82(48 \%)$ sporulated, the remaining cultures dying or forming sclerotia. The length of the vegetative stage differed greatly from culture to culture and tended to be longer and more variable at the end of the 2-year laboratory cultivation than at the beginning.

In a group of unsubcultured cultures similar to the above addition of oatmeal was stopped after a period of feeding. This starvation of previously well-fed cultures did not promote sporulation.

Effect of other nutrients. The following nutrients were used in place of ground oatmeal: aqueous oatmeal extract, ethanolic oatmeal extract, malt agar, and oak bark and valonia (the dried acorn-cups of Quercus aegilops), both obtained from the tannery from which Fuligo septica was obtained. The plasmodium did not sporulate when these materials were tested as alternatives to oatmeal.

Physical nature of solid substrate. This was varied, filter paper, cotton wool and glass surfaces being used. No effect on sporulation of the plasmodium was observed.

Light. Cultures (unsubcultured) maintained as in the experiments on the effect of age of culture were exposed to daylight for 16-18 hr. per day. Light did not induce fruiting under our conditions.

Temperature. Cultures (subcultured and unsubcultured) maintained as in the experiments on effect of age of culture were incubated at $30^{\circ}$ for 15 months after which incubation of this line of cultures was continued at $25^{\circ}$. Subculture to fresh medium prevented sporulation at $30^{\circ}$ as it did at $25^{\circ}$. At $30^{\circ}$ a lower frequency of sporulation $(33 \%)$ in unsubcultured plasmodia occurred than at $25^{\circ}$, although on transfer of this line of cultures from $30^{\circ}$ to $25^{\circ}$ sporulation was apparently stimulated $(82 \%)$. However, the number of cultures (44) used in this experiment was too small for any firm conclusion to be reached about this apparent stimulation of sporulation. 
Desiccation. Cultures maintained as in the experiments on effect of age on culture were allowed to desiccate slowly at $\mathbf{2 5}^{\circ}$. This did not induce sporulation.

\section{Attempts to induce sporulation}

The sporulation plasmodia used in these experiments were produced in cultures maintained as described in the experiments on the effect of age of culture. Attempts were made to demonstrate the existence in sporulating plasmodium of a substance inducing sporulation: (i) sporulating plasmodium (detectable at least $24 \mathrm{hr}$. before completion of the process) was transferred to a wet sterile cellophan membrane which separated the sporulating plasmodium from a vegetative plasmodium; (ii) sporulating plasmodium was transferred directly to vegetative plasmodium; (iii) freshly formed aethalium was transferred to vegetative culture; (iv) vegetative plasmodium was transferred to a culture which had just sporulated. All these attempts to show the existence of any inducing substance or substances in sporulating plasmodium, aethalium or culture medium were unsuccessful.

\section{Attempts to interrupt the sporulation process}

Attempts to interrupt sporulation were made by transferring sporulating plasmodium from cultures similar to those used in the previous section, to similar fresh culture medium, to a vegetative plasmodium in similar culture, to Cohen's agar and to malt agar, and by adding to sporulating plasmodium fresh nutrient in the form of powdered oatmeal or a suspension of a yeast isolated from plasmodium.

Transfer of sporulating plasmodium to a vegetative plasmodium, to Cohen's agar or to malt agar interrupted the sporulation process, the plasmodium returning to its normal vegetative state. Sporulating plasmodium transferred to similar fresh oatmeal medium, however, continued sporulation to completion. It is possible since only a few samples of plasmodium were used in the latter experiment (owing to the difficulty of detecting early stages of fruiting), that this difference in observations was due to the length of time after onset of sporulation at which the transfers were made. An irreversible stage in the sporulation process may have been reached in the latter case. The addition of fresh nutrient to sporulating plasmodia had no effect on the sporulation process.

\section{Spore germination}

A few experiments on spore germination were carried out with unpurified spore material produced in laboratory stock cultures of Fuligo septica as described in the previous section. Germination in distilled water of two batches of spores, one batch used immediately after formation and the other after storage for 6 months in a dry state at room temperature, was observed. The spores germinated by one of the methods described by Gilbert $(\mathbf{1 9 2 8} b)$ in which the swarm cell escapes through a wedge-shaped aperture in the spore wall. This aperture was readily observable on microscopic observation. When determination was made of $\%$ germination 300 spores were counted at random throughout the preparation and the number of these which had germinated recorded. $F$. septica spores showed no dormancy period in distilled water; newly formed spores germinated as well as those 6 months old. A high percentage germination (60-70\%) occurred within a few hours. 
Newly formed spores were also inoculated to stock culture medium; they germinated readily on the moist filter-paper support and in the presence of ground oatmeal developed into normal plasmodium. The young plasmodium ingested large numbers of the remaining spores, which gave it a dark brown appearance.

Since Elliot (1949) showed improved germination of some myxomycete spores after treatment with bile salts this was tested for Fuligo septica. Spores (4 months old) were shaken for a few minutes in a solution (10 g./1.) of bile salts, washed three times in sterile distilled water, resuspended in distilled water and incubated. Since the $\%$ germination without this treatment was usually high, and plasmodium readily obtained, treatment with bile salts showed no advantage.

Observation on the effect of cold and heat shock on spores (6 months old) was made by exposing them in distilled water suspension to the following temperatures: $-20^{\circ}$ for $30 \mathrm{~min} .2^{\circ}$ for $30 \mathrm{~min} ., 60^{\circ}$ for $5 \mathrm{~min}$., $60^{\circ}$ for $10 \mathrm{~min}$., $60^{\circ}$ for $20 \mathrm{~min}$., $60^{\circ}$ for $30 \mathrm{~min}$. The suspensions were then incubated in distilled water. Exposure to low temperatures (Table 3 ) before germination decreased the \% germination; $-20^{\circ}$ had a greater effect than $2^{\circ}$. Treatment at $60^{\circ}$ resulted in failure to germinate except in spores exposed for only $5 \mathrm{~min}$., where less than $1 \%$ germination occurred after 2 weeks.

Table 3. Germination at $\mathbf{2 5}^{\circ}$ of Fuligo septica spores after exposure in aqueous suspension to different temperatures

$\begin{array}{ccc}\begin{array}{c}\text { Exposure } \\ \text { temperature }\end{array} & \begin{array}{c}\text { Exposure time } \\ \text { (min.) }\end{array} & \begin{array}{c}\text { Germination } \\ \text { after 24 hr. } \\ \text { incubation } \\ (\%)\end{array} \\ 20^{\circ} & 30 & 22 \\ 2^{\circ} & 30 & 44 \\ 60^{\circ} & 5 & 0 * \\ 60^{\circ} & 10 & 0 \\ 60^{\circ} & 20 & 0 \\ 60^{\circ} & 30 & 0 \\ \text { None } & \text { None } & 69 \\ *<1 \% \text { germination after 14 days incubation. }\end{array}$

The effect of spore concentration was investigated. An arbitrary, fairly concentrated, suspension of spores ( 7 months old) containing 51,000 spores $/ \mathrm{mm}^{3}$ as determined by a haemacytometer count, was prepared in distilled water and diluted $1 / 2,1 / 3,1 / 4,1 / 5,1 / 6,1 / 8$ and $1 / 16 ; 0.02 \mathrm{ml}$. samples of each dilution were set up in a van Tieghem cell and the \% germination recorded at intervals. The more dilute suspensions of spores showed earlier and higher \% germination than the more concentrated suspensions (Table 4).

\section{DISCUSSION}

Fuligo septica, a myxomycete which has not been much used in work with the slime moulds, can be readily grown in unpurified culture in the laboratory, and will complete its life cycle, fruiting and germination, under such conditions. It is therefore a suitable organism for laboratory study. Environmental conditions which favour the growth of $F$. septica are similar to those found by other workers 
Table 4. Germination at $25^{\circ}$ of Fuligo septica spores in aqueous suspensions of different concentrations

The initial suspension contained 51,000 spores $/ \mathrm{mm} .{ }^{3}$ as determined by a haemacytometer count.

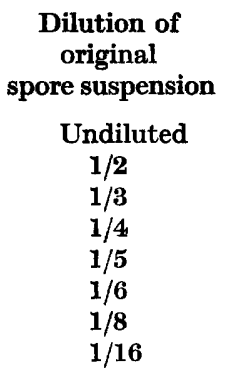

\begin{tabular}{rrrr}
\multicolumn{4}{c}{ Germination (\%) at } \\
\hline $2 \mathrm{hr}$. & $3.5 \mathrm{hr}$. & $6 \mathrm{hr}$. & $24 \mathrm{hr}$. \\
0 & $<1$ & $<1$ & 14 \\
0 & 0 & $<1$ & 18 \\
0 & 0 & $<1$ & 19 \\
0 & $<1$ & $<1$ & 7 \\
0 & 0 & $<1$ & 6 \\
0 & 0 & $<1$ & -17 \\
$<1$ & $<1$ & 12 & 48
\end{tabular}

to be suitable for other myxomycete species. For example Hok (1950) found that growth of Physarum polycephalum was good between $\mathrm{pH} \mathrm{4.0}$ and $7 \cdot 0$ and between $18^{\circ}$ and $25^{\circ}$. Badhamia sp. similarly tolerated a wide $\mathrm{pH}$ range, $\mathrm{pH} 4 \cdot 0-7 \cdot 5$ (Jahn, 1932). B. utricularis (Sobels, 1950) grew well at $20^{\circ}-24^{\circ}$, was slightly inhibited at $30^{\circ}$ and died at $35^{\circ}$. In the present work $F$. septica grew well between $\mathrm{pH} 4.5$ and 7.5 and over a temperature range of $18^{\circ}-30^{\circ}$. Like $P$. polycephalum (Moore, 1935; Allen \& Price, 1950) F. septica was found to be aerobic. In contrast to the findings of Hofmeister (1867) and Stahl (1884) who reported positive phototaxis of $F$. septica in weak light, in the present work $F$. septica was negatively phototactic. $B$. utricularis was shown by Sobels (1950) to be negatively phototactic. As observed by Gray (1938) the yellow pigmentation of $F$. septica was lost in the light. Growth was initially retarded in the light but exposure to direct sunlight was not lethal (cf. Gray, 1938).

The growth of Fuligo septica was better when nutrient was available in particulate form than when soluble nutrients only were present. A similar observation was made by Hok (1950) for Physarum polycephalum. P. polycephalum has since, however, been grown successfully in pure culture on a non-particulate medium (Daniel \& Rusch, 1956, 1961), thus showing that this organism has not the specific requirement for particulate nutrient which has from time to time been postulated for this group of organisms.

Many of the earlier workers who claimed to have established two-member or axenic cultures appear to have used insufficiently rigorous and comprehensive tests for purity and their claims must be accepted with some reserve (e.g. Vouk, 1913; Skupienski, 1928; Howard, 1931; Cohen, 1939). Of these workers, some found that two-member cultures could readily be achieved with several bacterial, yeast or mould species (e.g. Vouk, 1913; Skupienski, 1928; Cohen, 1941; Hok, 1950), whilst others found such cultures more difficult to establish (e.g. Cohen, 1939; Sobels, 1950). In the present work Fuligo septica grew well in two-member culture only with two yeasts and a Penicillium sp. which had all been isolated from plasmodium, and with a laboratory strain of Saccharomyces cerevisiae. The myxomycete showed little or no continuing growth with a variety of Gram-positive and Gramnegative bacteria, some isolated from plasmodium and some from other sources. It is possible that particle size and the capacity of the plasmodium to ingest such 
material may have some bearing on the nature of organisms suitable for twomember cultures. Gilbert (1928 $a$ ) observed that swarm cells and small plasmodia of Dictydiaethalium plumbeum would ingest only smaller fungus spores. Kidder, Dewey \& Fuller (1954) suggested that size of certain food molecules was important for some protozoal species. Axenic culture of $F$. septica, as found by Sobels (1950), proved difficult in our work, a small amount of growth being obtained with only one preparation from autoclaved baker's yeast.

Although sporulation of Fuligo septica occurred regularly in the laboratory, the presence of an inducing substance in the cultures could not be demonstrated, and the factors causative in the sporulation process were not determined. As observed by Seifriz \& Russell (1936) with Physarum polycephalum, however, a definite rhythm of sporulation occurred, subculture within a certain period always averting sporulation. Seifriz \& Russell suggested that the presence of 'toxic' or stimulatory substances in old cultures is the factor which most probably precipitates sporulation. The present observations with $F$. septica are in accordance with this interpretation. The interruption of the sporulation process which occurred on subculture is explicable by removal of the sporulating plasmodium from the influence of such substances. The possible effect of size of plasmodium as a pre-conditioning factor is also worthy of investigation (cf. Hok, 1950). In contrast to the findings of Gray (1938) with $F$. septica and $P$. polycephalum and of Hok (1950) with $P$. polycephalum, light was not found to be necessary for sporulation of $F$. septica, nor was it a precipitating factor. Depletion of nutrient did not lead to sporulation as it did with P. polycephalum (Camp, 1937).

A high percentage of spore germination was obtained with Fuligo septica in distilled water within $24 \mathrm{hr}$., as found by Gilbert (1929) and Smart (1937) and contrary to Cook \& Holt's finding (1928) with this species. Dilute suspensions of $F$. septica spores showed a markedly higher percentage of germination than more concentrated suspensions, in contrast to the findings of Smart (1937) and Wilson \& Cadman (1928) with other myxomycete species. Powell (1957) found that the germination of spores of Bacillus subtilis was less complete and slower in concentrated suspensions than in dilute suspensions. Thus the spores themselves may produce substances inhibitory to germination, as has been found for some fungal species (Allen, 1955; Krishnan, Bajaj \& Daml, 1954).

I wish to express my sincere thanks to Professor B. C. J. G. Knight for his continued advice and criticism during this work, and for his criticism of the manuscript.

\section{REFERENCES}

Alexopoulos, C. J. (1960). Morphology and laboratory cultivation of Echinostelium minutum de Bary. Amer. J. Bot. 47, 37.

Allen, P. J. (1955). The role of a self-inhibitor in the germination of rust uredospores. Phytopathology, 45, 259.

Allen, P. J. \& Price, W. H. (1950). The relation between respiration and protoplasmic flow in the slime mould Physarum polycephalum. Amer. J. Bot. 37, 393.

Baranetzki, J. (1876). Influence de la lumière sur les plasmodia des myxomycètes. Mém. Soc. Sci. nat. Cherbourg, 19, 321.

CAMP, W. G. (1936). A method of cultivating myxomycete plasmodia. Bull. Torrey bot. Cl. 63, 205. 
CAMP, W. G. (1937). The fruiting of Physarum polycephalum in relation to nutrition. Amer. J. Bot. 24, 300.

Cohen, A. L. (1939). Nutrition of the myxomycetes. I. Pure culture and two-membered culture of myxomycete plasmodia. Bot. Gaz. 101, 243.

Conen, A. L. (1941). Nutrition of myxomycetes. II. Relations between plasmodia, bacteria and substrate in two-membered culture. Bot. Gaz. 103, 205.

Cook, W. R. I. \& HoLT, E. M. (1928). Some observations on the germination of the spores of some species of mycetozoa. Mycologia, 20, 340.

Daniel, J. W. \& Rusch, H. P. (1956). Growth of a plasmodial slime mold in pure culture on a soluble medium. Fed. Proc. 15, 513.

DANIEL, J. W. \& Rusch, H. P. (1961). The pure culture of Physarum polycephalum on a partially defined soluble medium. J. gen. Microbiol. 25, 47.

ElLiot, E. W. (1949). The swarm cells of myxomycetes. Mycologia, 41, 141.

Gilbert, F. A. (1928a). Feeding habits of swarm cells of the myxomycete Dictydiaethalium plumbeum. Amer. J. Bot. 15, 123.

GiLBert, F. A. $(1928 b)$. A study of the method of spore germination in the myxomycetes. Amer. J. Bot. 15, 345.

Gilbert, F. A. (1929). Factors influencing the germination of myxomycetous spores. Amer. J. Bot. 16, 280.

Gray, W. D. (1938). The effect of light on the fruiting of myxomycetes. Amer. J. Bot. 25, 511.

Gray, W. D. (1961). The laboratory cultivation of Physarum flavicomum. Amer. J. Bot. 48, 242.

Hofmeister, W. F. B. (1867). Lehre von der Pflanzenzelle. Leipzig.

Hor, K. A. (1950). Pure culture studies of mycetozoa with emphasis on nutrition, life cycle and carbohydrate metabolism of Physarum polycephalum. Thesis, University of California.

Hoк, K. A. (1954). Studies of the nutrition of myxomycete plasmodia. Amer. J. Bot. 41, 792.

Howard, F. L. (1931). The life history of Physarum polycephalum. Amer. J. Bot. $18,116$.

JAHN, E. (1932). Die Organe des Plasmodiums. Ber. dtsch. bot. Ges. 50 A, 367.

Kerr, N. S. \& Sussman, M. (1958). Clonal development of the true slime mould, Didymium nigripes. J. gen. Microbiol. 19, 173.

KIDDER, G. W., Dewey, V. C. \& Fuller, R. C. (1954). Nitrogen requirements of Glaucoma scintillans and Colpidium campylum. Proc. Soc. exp. Biol., N.Y. 86, 685.

Krishnan, P. S., BaJaJ, V. \& Damle, S. P. (1954). The growth of Aspergillus niger from spore inoculum. Appl. Microbiol. 2, 303.

Moore, A. R. (1935). On the significance of cytoplasmic structure in plasmodium. J. cell. comp. Physiol. 7, 113.

Powell, J. F. (1957). Biochemical changes occurring during spore germination in Bacillus species. J. appl. Bact. $20,349$.

Seifriz, W. \& Russel., M. A. (1936). The fruiting of myxomycetes. New Phytol. 35, 472.

Skupienski, F. X. (1928). Étude bio-cytologique du Didymium difforme. Acta Soc. bot. polon. 5, 255.

SMART, R. F. (1937). Influence of external factors on spore germination in the myxomycetes. Amer. J. Bot. 24, 145.

Sobels, J. C. (1948a). Contribution à l'étude physiologique de myxomycètes. Ann. Inst. Pasteur, 75, 147.

Sobels, J. C. (1948b). Sur un extrait aqueux de myxomycètes, empêchant la croissance de Torulopsis histolytica. C.R. Acad. Sci., Paris, 226, 1030.

Sobels, J. C. (1950). Nutrition de quelques myxomycètes en cultures pures et associées et leurs propriétés antibiotiques. Antonie van Leeuwenhoek J. Microbiol. Serol. 16, 123.

Stahl, E. (1884). Zur Biologie der Myxomyceten. Bot. Ztg, 48, 143.

Vouk, V. (1913). Untersuchungen über die Bewegung der Plasmodien. 1. Die Rhythmik der Protoplasmaströmung. Naturwissenschaften, 1, 81.

Wilson, M. \& Cadman, E. J. (1928). The life history and cytology of Reticularia lycoperdon Bull. Trans. R. Soc. Edin. 55, 555. 